\title{
A INFLUÊNCIA DA FÉ NO TRATAMENTO DE PACIENTES ONCOLÓGICOS
}

DOI: 10.22289/2446-922X.V7N2A14

\author{
Catia Almeida Alves da Silva ${ }^{1}$ \\ Karina Aparecida Ferreira da Rocha \\ Luiz Roberto Marquezi Ferro \\ Aislan José de Oliveira \\ Márcia Guimarães Rivas
}

\section{RESUMO}

O câncer é considerado uma doença muito antiga e a sua origem pode estar associada a diversos fatores. Configura-se como um grave problema de saúde pública mundial e com altos índices de casos. Diante do possível diagnóstico da doença, surgem vários sentimentos no indivíduo, pois o futuro se torna temido e desconhecido para ele. Neste processo, o psicólogo utiliza o seu conhecimento técnico para ajudar a reduzir os impactos causados pela doença, contribuindo em um cuidado completo e identificando possíveis desordens psíquicas. A fé torna-se uma alternativa significativa que pode resultar em esperança, fortalecimento e equilíbrio; através dela é possível identificar a importância em aceitar a doença e lidar com o processo de tratamento, melhorando a qualidade de vida do sujeito neste momento e intensificando a sua luta contra a enfermidade. $O$ objetivo deste estudo foi identificar a influência da fé no tratamento de pacientes oncológicos que faziam tratamento em uma unidade hospitalar na capital paulista. Trata-se de uma pesquisa qualitativa com a participação de sete sujeitos; esse número se fixou por ocasião da exaustão do discurso. Os mesmos foram selecionados de maneira randômica e que manifestaram o consentimento em participar da pesquisa. Os participantes responderam a um roteiro de entrevista semiestruturado. A análise dos resultados foi feita por meio de Análise de Discurso com a construção de categorias. Em relação aos resultados esperados, consideramos que a fé é um recurso positivo para o enfrentamento do câncer e que este fenômeno contribui significativamente para o processo de tratamento da doença.

Palavras-chave: Promoção de Saúde; Psico-Oncologia; Espiritualidade, Religião; Cuidados Paliativos.

\section{THE INFLUENCE OF FAITH IN THE TREATMENT OF CANCER PATIENTS}

\section{ABSTRACT}

The cancer has been studied for a long time and some conclusions of these illness should be associate of many reasons. According some researches, this illness has been considered one of the biggest public health problem around the world and with many cases registered. Everybody who is in front of possibility to positive diagnostic of cancer can be negative feelings or thoughts about the

\footnotetext{
${ }^{1}$ Endereço eletrônico de contato: catiasilva.7719@aluno.saojudas.br

Recebido em 21/07/2021. Aprovado pelo conselho editorial para publicação em 22/09/2021.
} 
future and their uncertainties. The psychologist should contribute with the mental process by using technical knowledge to help people and mental impacts caused because the illness and contribute with a complete care identifying potentials psychical disorders. In this process the faith becomes a significant alternative to the treatment, could result in trust and power of balance. The faith should be represented part of a process to understand and take on lidding with the cancer, improving the life quality and intensifying the struggle of illness. The focus on this studying was identifying the influence of faith on oncological patients' treatment on hospital unit in São Paulo from capital. It was about a qualitative research and were considered seven people with the same repetitive talks after had been interviewed. The people selection was random, inside the hospital and all of participants was interviewed following a guide prepared before of the researches. The analyses results were produced about the "Talk Analyses or Speech Analyses" making the categories. In terms of expected results, the faith was considered a positive alternative and source to face or to feel of cancer. The faith phenomenon can contribute significantly to the cancer treatment process.

Keywords: Health Promotion; Psycho-oncology; Spirituality, Religion; Palliative Care.

\section{LA INFLUENCIA DE LA FE EN EL TRATAMIENTO DE LOS PACIENTES CON CÁNCER}

\section{RESUMEN}

El cáncer se considera una enfermedad muy antigua y su origen puede estar asociado a varios factores. Se configura como un grave problema de salud pública a nivel mundial y con altas tasas de casos. Ante el posible diagnóstico de la enfermedad, surgen en el individuo diversos sentimientos, ya que el futuro se vuelve temido y desconocido para él. En este proceso, el psicólogo utiliza sus conocimientos técnicos para ayudar a reducir los impactos causados por la enfermedad, contribuyendo a la atención completa e identificando posibles trastornos psíquicos. La fe se convierte en una alternativa significativa que puede resultar en esperanza, fortaleza y equilibrio; a través de él se puede identificar la importancia de aceptar la enfermedad y afrontar el proceso de tratamiento, mejorando la calidad de vida del sujeto en este momento e intensificando su lucha contra la enfermedad. El objetivo de este estudio fue identificar la influencia de la fe en el tratamiento de pacientes oncológicos en tratamiento en un hospital de la ciudad de São Paulo. Es una investigación cualitativa con la participación de siete sujetos; este número se fijó en el momento del agotamiento del discurso. Fueron seleccionados al azar y quienes expresaron su consentimiento para participar en la investigación. Los participantes respondieron un guión de entrevista semiestructurado. El análisis de los resultados se realizó a través del Análisis del Discurso con la construcción de categorías. En cuanto a los resultados esperados, creemos que la fe es un recurso positivo para combatir el cáncer y que este fenómeno contribuye significativamente al proceso de tratamiento de la enfermedad.

Palabras clave: Promoción de la Salud; Psicooncología; Espiritualidad, Religión; Cuidados paliativos.

\section{INTRODUÇÃO}

O câncer é um grave problema de saúde pública mundial e se enquadra entre as quatro principais causas de mortes prematuras, antes dos 70 anos de idade, na maior parte da população global. Há um aumento no índice de casos e na mortalidade no mundo todo, e os dados mais 
recentes registram a ocorrência de 18 milhões de novos casos e 9,6 milhões de óbitos. Os cânceres de pulmão e mama possuem os maiores índices mundiais de diagnósticos, com 2,09 milhões de casos cada; os de cólon e reto ou colorretal possuem 1,80 milhão e o de próstata 1,28 milhão de casos; os cânceres de pele (não melanoma) e estômago também aparecem no ranking com 1,04 e 1,03 milhões de casos, respectivamente (World Health Organization [WHO], 2018).

Segundo as estimativas de incidência de câncer para o Brasil, os tipos de cânceres mais presentes nos homens foram os de pulmão, próstata, cólon e reto, estômago e fígado. Já nas mulheres, os mais frequentes foram os cânceres de mama, cólon e reto, pulmão e colo do útero (Instituto Nacional de Câncer [INCA], 2020).

A ocorrência para 2020-2022 indica que acontecerão 625 mil novos casos de câncer no Brasil, sendo o câncer de pele não melanoma com maior diagnóstico com 177 mil casos e, em seguida, os cânceres de mama e próstata com 66 mil novos casos cada; na sequência, o câncer do cólon e reto com 41 mil casos, o câncer de pulmão com 30 mil casos e, por fim, o câncer de estômago com 21 mil casos (INCA, 2020).

Analisando os dados dos índices de câncer no Brasil, os de maior incidência nos homens serão os de próstata, cólon e reto, pulmão, estômago e cavidade oral. Nas mulheres, estima-se que os tipos principais sejam os de mama, cólon e reto, colo do útero, pulmão e tireoide. O câncer de pele não melanoma acometerá $27,1 \%$ de todos os casos em homens e $29,5 \%$ em mulheres (INCA, 2020).

O câncer é definido como um grande grupo de doenças que têm em comum o crescimento desordenado de células que invadem tecidos e órgãos. Em uma rápida divisão, elas tendem a ser muito agressivas e incontroláveis, determinando, assim, a formação de tumores que podem espalhar-se para outras partes do corpo. O câncer, também conhecido como tumor maligno ou neoplasia, pode afetar qualquer parte do corpo; o último processo é conhecido como metástase (WHO, 2018).

A Oncologia é uma área da Medicina que estuda o câncer, sendo assim, a Psico-Oncologia é uma área da Psicologia que trabalha o cuidado junto ao paciente com câncer. O paciente que adoece passa por questões internas relacionadas às experiências de dor, perda e luto resultantes da doença e do tratamento (Christo \& Traesel, 2009).

O câncer pode representar uma ameaça ao destino de uma pessoa e desencadear inúmeros sentimentos como, por exemplo, impotência, desânimo, temor e aflição. O diagnóstico pode ser acompanhado de depressão, possivelmente pela falta de aceitação da doença. Através dos desgastes físico e emocional que se apresentam durante os procedimentos terapêuticos invasivos, o paciente é tomado pelos sentimentos de raiva, medo, angústia, pena de si e pela sensação de ter perdido o controle da sua vida (Silva, Aquino, \& Santos, 2008).

O câncer vai além de uma dor física ou um desconforto, pois interfere na família, no trabalho e na renda do paciente; sua mobilidade, sua imagem corporal e seu estilo de vida podem sofrer 
drásticas alterações. Estas mudanças podem ser provisórias ou definitivas, produzindo impacto a todos os envolvidos direta ou indiretamente, pois cada pessoa enxerga o mundo de forma única (Silva \& Cruz, 2011).

A notícia do diagnóstico de câncer pode alterar significativamente o relacionamento entre os membros da família, a comunicação e a resolução de questões diárias. Alguns dos problemas que surgem em relação ao diagnóstico são: dificuldades econômicas pelos gastos com os tratamentos, ocultação do diagnóstico como forma de reduzir comentários não desejados, conflitos familiares que podem atrapalhar o suporte necessário e as adaptações e mudanças nos hábitos de vida (Farinhas, Wendling, \& Dellazzana-Zanon, 2013).

Em relação ao estresse causado pelo câncer, a família pode apresentar queixas resultantes dos sofrimentos emocional, psicológico e físico do paciente. Esse estresse é causado pelas demandas e consequências dos tratamentos como, por exemplo, internações, quimioterapias, cirurgias e sessões de radioterapia, sendo assim, a família é incluída em um mundo que a amedronta. A família possui influência positiva ou negativa sobre o processo de tratamento do câncer, logo, é recomendado que ela receba tratamento psicológico (Farinhas et al., 2013).

Devido ao temor que o câncer desenvolve na vida do paciente, os transtornos psíquicos são recorrentes e podem levar à diminuição da qualidade de vida do sujeito. Sendo assim, o papel do psicólogo junto ao paciente com diagnóstico de câncer é identificar os conteúdos que estão associados à queixa, atenção nos sintomas e na patologia, proporcionando um cuidado completo e identificando possíveis desordens psíquicas que geram sofrimento e estresse. Isso contribui para a ressignificação da doença e possibilita que o paciente participe do seu processo de tratamento (Ferreira, Lopes, \& Melo, 2011).

Desta forma, o psicólogo se dedica a minimizar os efeitos provocados pela doença, contribuindo na reintegração do paciente à sociedade e auxiliando para uma rotina semelhante à que ele tinha antes do diagnóstico. Além da intervenção técnica do psicólogo, a empatia e a escuta devem estar presentes neste momento, pois favorecem no enfrentamento dos conteúdos internos do paciente. A partir desse processo de enfrentamento, há a possibilidade de aceitação, elaboração e superação frente ao adoecimento (Ferreira et al., 2011).

Apesar das inúmeras formas de tratamento e o constante avanço da ciência para cuidados com os pacientes com câncer, essa ainda é uma doença temida e considerada incurável por muitas pessoas, pois apesar dos meios para tratar a neoplasia existirem, muitas vezes são considerados ameaçadores, agressivos e invasivos, deixando o paciente ainda mais fragilizado e vulnerável diante de tal situação, potencializando a insegurança num provável fracasso no tratamento. Desta maneira, os pacientes e suas famílias, diante da desesperança, buscam alternativas para enfrentar este processo doloroso e incerto de forma positiva e reconfortante, como, por exemplo, a espiritualidade (Gayer, 2013). 
A espiritualidade pode se tornar uma forma de enfrentamento em relação ao diagnóstico; o paciente pode ressignificar o seu processo de cura-doença, buscando uma maior qualidade de vida, alívio da angústia e esperança diante do processo. Neste caso, na possibilidade de um provável desânimo ou desistência, a fé é primordial para a possível retomada e continuidade do tratamento (Soratto, Silva, Zugno, \& Daniel, 2016).

Apesar de os termos espiritualidade e fé se conectarem, eles possuem características particulares e diferentes, assim como um terceiro termo que também discutiremos aqui: a religião. E é importante distingui-los desde já para que tenhamos uma melhor compreensão do que trataremos mais à frente.

Espiritualidade é um conceito mais amplo do que religião; diz respeito àquilo que dá sentido à vida. É um entendimento mais transcendente, ou seja, que justifica questões como o porquê e para quê existimos. Está além do que se pode ver e compreender. É um sentimento pessoal que impulsiona o ser humano a se preocupar consigo e com as demais pessoas a sua volta e tem a capacidade de fazer com que ele suporte situações debilitantes, onde a dor, a culpa, a ansiedade e a raiva são inevitáveis (Saad, Masiero, \& Battistella, 2001).

Seguindo nesta linha, a religião pode ser compreendida como parte da espiritualidade, visto que cabe a esta um conceito mais dogmático, isto é, a adesão a práticas que o indivíduo acredita e segue, como, por exemplo, a participação em templo religioso, leitura de livros religiosos e orações compartilhadas em grupo (Saad et al., 2001).

Vinda do latim, religio, formada com o prefixo "re" (outra vez, de novo) e o verbo ligare (ligar, unir, vincular), religião significa a tentativa de religar o ser humano à divindade, o profano ao sagrado; reconectar algo que foi desfeito, destituído (Cerqueira-Santos, Koller, \& Pereira, 2004).

A fé, por sua vez, é definida na Bíblia Sagrada como "[...] a certeza de coisas que se esperam, a convicção de fatos que se não veem." (Hebreus, capítulo 11, versículo 1, versão Almeida Revista e Atualizada [ARA]). Sendo assim, entendemos esta como resultado da esperança, do fortalecimento e do equilíbrio, ou seja, emana a possibilidade de aceitação em lidar com a doença e o seu processo de tratamento, intensificando a força de lutar contra a enfermidade (Ouro, Sodré, Figueiredo, Souto, Fernandes, \& Fernandes, 2018).

Desse modo, nosso objetivo foi avaliar se a fé exerce alguma influência ao longo do tratamento do paciente oncológico e a inferência na qualidade de vida do indivíduo, sob a hipótese de que pacientes oncológicos com fé (expressão religiosa) tendem a ter maiores benefícios no tratamento da doença.

\section{MATERIAIS E MÉTODOS}


Neste estudo, utilizamos a modalidade de pesquisa qualitativa. A pesquisa qualitativa traz à tona questões particulares, empenhando-se no universo de significados, motivos, aspirações, crenças, valores e atitudes, portanto, insere-se no mundo dos significados das ações e relações humanas (Minayo, 2002).

O estudo foi desenvolvido com pacientes com câncer que faziam tratamento em uma unidade hospitalar situada na cidade de São Paulo. Entrevistamos sete participantes, selecionados de maneira randômica.

Em pesquisa qualitativa não há um fundamento numérico para garantir uma representatividade (Deslandes, 2002), logo, o fechamento amostral se deu por saturação, ou seja, suspendemos a coleta de dados quando os discursos dos pacientes começaram a se repetir. No fechamento amostral por saturação, há a descontinuação da inclusão de novos participantes quando os dados atingidos apresentam, na avaliação do pesquisador, redundância ou repetição, não sendo necessário persistir na coleta de dados (Fontanella, Ricas, \& Turato, 2008).

Foram utilizados como critérios de inclusão: pacientes maiores de 18 anos, legalmente capazes, diagnosticados com qualquer tipo de neoplasia maligna, que estavam realizando tratamento contra a doença na Instituição selecionada e que aceitaram participar conscientemente da pesquisa assinando o Termo de Consentimento Livre e Esclarecido (TCLE).

$\mathrm{Na}$ coleta de dados, aplicamos um questionário sociodemográfico com 12 perguntas e realizamos uma entrevista semiestruturada com 19 perguntas.

Nosso trabalho seguiu as normas estabelecidas pelo Conselho Nacional de Saúde (CNS), Resolução no 466, de 12 de dezembro de 2012, envolvendo pesquisa científica com seres humanos.

O projeto foi encaminhado ao Comitê de Ética em Pesquisa da Universidade São Judas Tadeu (CEP/USJT) e, após aprovação, ao Comitê de Ética em Pesquisa do Instituto Brasileiro de Controle do Câncer (CEP/IBCC) para as devidas apreciação e validação, sob os números: CAAE 41120620.0.0000.0089, do CEP/USJT, e CAAE: 41120620.0.3001.0072, do CEP/IBCC.

A aplicação dos instrumentos foi feita de forma presencial e individual, em dia e horário agendados com o setor responsável na Instituição, resguardando as condições de conforto e privacidade; o tempo de aplicação foi de até, aproximadamente, 40 minutos por participante.

Por se tratar de uma pesquisa de campo que foi realizada durante o período de fase emergencial do plano do Estado de São Paulo para a pandemia pela COVID-19, seguimos rigorosamente as medidas sanitárias impostas pela Organização Mundial da Saúde (OMS) durante a coleta de dados na Instituição.

Os dados levantados foram transcritos de forma fiel, em recortes, ao longo da discussão do estudo. Empregamos a Análise de Discurso, para a qual realizamos a construção de categorias temáticas para a compreensão do fenômeno estudado (Minayo, 2006), estabelecendo articulações entre os dados e os referenciais teóricos que selecionamos para a pesquisa. 


\section{RESULTADOS E DISCUSSÃO}

Realizamos a nossa pesquisa contando com a participação de sete pacientes, todas do sexo feminino, internadas na unidade hospitalar selecionada, cada uma realizando um tipo de tratamento diferente contra o câncer. No setor de internações do hospital havia dois pacientes do sexo masculino internados, porém não estavam disponíveis para as entrevistas no horário que as realizamos.

Vários estudos constatam que, em geral, homens padecem mais de condições severas e crônicas de saúde do que mulheres, e também morrem em maior número pelas principais causas de morte. Sobretudo, a quantidade de homens nos serviços de atenção primária à saúde é inferior à das mulheres (Gomes, Nascimento, \& Araújo, 2007).

Estudo aponta a necessidade de refletir sobre masculinidade a fim de compreender o porquê da menor intensidade com os cuidados à saúde. O imaginário de ser homem pode aprisionar o masculino em questões culturais que dificultam as práticas de autocuidado, pois à medida que o homem é visto como viril, invulnerável e forte, procurar um serviço de saúde, numa perspectiva preventiva, poderia associá-lo à fraqueza, medo e insegurança, o que consequentemente o aproximaria das representações do universo feminino, implicando numa possível desconfiança de sua masculinidade socialmente instituída (Gomes et al., 2007).

Contudo, podem coexistir outros fatores que dificultam o acesso do homem a serviços de saúde, como o horário de trabalho que pode coincidir com o horário de funcionamento dos locais que prestam serviços à saúde, acessibilidade, especificidades das equipes profissionais e a estrutura de funcionamento desses serviços, dentre outros (Alves, Silva, Ernesto, Lima, \& Souza, 2011).

As idades das pacientes variaram de 32 a 72 anos, e a maioria, havia recebido diagnóstico de metástase, sem previsão de quando encerrariam os tratamentos.

A metástase é um processo complexo no qual as células cancerosas de um tumor disseminam-se para o corpo, formando tumores satélites, distantes do tumor original. Este fator, por si só, já representa um agravante para a piora do quadro clínico do paciente e para a utilização de medicamentos mais avançados contra o tumor, o que aumenta consideravelmente a mortalidade associada à doença (Fabiani et al., 2019).

Outro ponto de destaque nos dados sociodemográficos, foi a maioria das entrevistadas serem pacientes com diagnóstico de câncer de mama. Esse dado evidencia os últimos estudos realizados no campo da saúde que apresentam o câncer de mama como o de maior incidência em mulheres no nosso país, representando uma taxa de 43,74 casos por 100.000 mulheres no ano de 2020. As regiões Sul e Sudeste são as que apresentam as maiores taxas de mortalidade no Brasil com 16,14 e 15,08 óbitos, respectivamente, por 100.000 mulheres em 2019. A incidência do câncer 
de mama tende a ser maior a partir dos 40 anos de idade, assim como a morte por essa neoplasia (INCA, 2021).

O câncer de mama é a neoplasia mais comum entre as mulheres, e as técnicas para rastreála envolvem o exame clínico e a mamografia. O exame clínico é feito através da palpação por profissionais treinados como forma de detectar tumores superficiais de até 1 centímetro de diâmetro, sendo indicado a partir dos 40 anos de idade. A mamografia é uma técnica radiográfica que localiza nódulos pequenos de poucos milímetros, sendo aconselhada a realização a cada dois anos para mulheres com idades entre 50 e 69 anos. Para mulheres consideradas de alto risco para o câncer de mama, indicam-se exames anuais a partir dos 35 anos de idade (Malzyner, 2013).

Dentre os tratamentos realizados pela maioria das participantes, estavam a radioterapia e a quimioterapia. A radioterapia é um tratamento que utiliza radiações ionizantes, e é um tipo de energia direcionada para eliminar ou impedir que as células tumorais aumentem; o paciente não sente nenhum incômodo durante a aplicação desta radiação. Já a quimioterapia é um tratamento que introduz na circulação sanguínea compostos químicos para o combate ao câncer; a medicação é administrada através de diversas formas, como, via oral, intravenosa, intramuscular, subcutânea, intratecal e tópica. Dependendo do tipo do tumor, a radioterapia pode ser combinada com a quimioterapia ou vice e versa. Essa combinação vai depender da espécie do tumor e da escolha do tratamento (Centro de Combate ao Câncer [CCC], n.d.).

Após a transcrição fiel das entrevistas, foi utilizada a Análise de Discurso em pesquisa qualitativa e, a partir disso, seis categorias foram criadas: "Apoio social", "Dependência, uma nova realidade", "Cura pela fé", "Religião em prática", "Relacionamento com a divindade" e, por fim, "Resiliência e a potencialização da fé".

\section{Apoio social}

Rede social e apoio social são conceitos diferentes, mas que podem se relacionar mutuamente. A rede social é formada por um grupo de pessoas no qual o indivíduo tem algum vínculo, como relacionamentos mais próximos e relacionamentos formais. O apoio social diz respeito a ter com quem "contar", por exemplo. O indivíduo pode ter uma rede social e não receber apoio desta rede (Santana, Zanin, \& Maniglia, 2008).

Para a diminuição do sofrimento psicológico, o apoio social é considerado pela literatura como peça fundamental nos suportes da saúde e da qualidade de vida, pois este tipo de assistência desenvolve impacto positivo nas saúdes física e mental, representando um método eficiente na luta contra a doença (Sette \& Capitão, 2018).

Relacionamentos mais próximos, como os de família, com suas ajudas material e emocional, são considerados um fator de apoio essencial no processo de tratamento do câncer, uma vez que estes proporcionam suporte importante que aumentam a adesão e as expectativas para se chegar 
até o fim da doença. Amigos próximos, que também podem compor estes tipos de relacionamentos, são ademais consideráveis, pois fazem com que os pacientes com câncer sintam-se lembrados. Além destes, outros tipos de relacionamentos podem vir a compor a rede social de um indivíduo, como colegas de trabalho ou faculdade e os membros da instituição religiosa que este frequente. $E$, uma vez que o paciente diagnosticado com câncer receba o apoio de sua rede social, pode apresentar uma melhora significativa em sua reabilitação, pois o apoio social pode ser definido como auxílio, força, companhia, aconselhamento ou ajuda, desde o momento em que o paciente recebe a notícia da neoplasia até o pós-tratamento desta (Alves et al., 2012).

Em algumas falas das entrevistadas, conseguimos observar o que a literatura traz:

Tabela 1 - Apoio social a pacientes oncológicos

\begin{tabular}{|c|c|}
\hline Paciente & Relato \\
\hline P6 & $\begin{array}{l}\text { [...] Eu tenho muita amizade, eu tenho muita gente me apoiando, orando } \\
\text { por mim... evangélico, quem é espiritual, quem é... acho que até } \\
\text { macumbeiro [...] }\end{array}$ \\
\hline P5 & $\begin{array}{l}\text { Ah, graças a Deus, eu tenho muito apoio. Primeiro da minha família, né? } \\
\text { A pessoa se não tiver família pra te apoiar, cê não consegue. Tá apoiando } \\
\text { bastante! }\end{array}$ \\
\hline P7 & $\begin{array}{l}{[. . .] \text { Ah, todo mundo dá aquela força: '[...] isso vai passar, isso vai sumir...'; }} \\
\text { todo mundo dá força. }\end{array}$ \\
\hline
\end{tabular}

Contudo, podemos observar que a falta de apoio social pode acentuar a dor e a solidão do paciente diagnosticado com algum tipo de neoplasia, além de gerar preocupações a mais das que o paciente já tem neste momento delicado:

Com as minhas filha é muito bom [o relacionamento], agora com meu marido, minha fia... É um desastre! Não dá pra confiar, não. O bicho pega. Que ele é muito zo... [...] Mesmo hoje... Quando eu pensei não, o momento que ele mais ia ajuda eu... ele não ajudou, inté hoje... nas costa [...] (P6)

Algumas pacientes haviam sido submetidas a cirurgia para remoção dos tumores, outras estavam em procedimento medicamentoso, outras em observação por alguma complicação no percurso do tratamento, por exemplo. Nesse âmbito, o processo de hospitalização marca intensamente o indivíduo e gera percepções únicas e cheias de sentido. Nesta ocasião, a atenção da família, amigos e profissionais da saúde torna-se mais significativa por meio do olhar diferenciado e humanizado (Santos, Santos, \& Melo, 2020). 
A pessoa internada em hospital necessita de acompanhante, e na maioria das vezes, um familiar realiza esta tarefa. O sentimento de ter o tempo de vida reduzido pela doença ou gravidade do acidente acentua no hospitalizado a necessidade de expressar e viver intensamente os seus sentimentos em relação aos amigos e familiares. A distância da família ou daqueles que são mais próximos pode trazer consigo a saudade destes que, em muitos casos, simbolizam o amor e o cuidado. Entretanto, as pessoas do círculo de maior proximidade, além de auxiliar diretamente no tratamento do paciente internado, podem auxiliar indiretamente pelo simples fato de existirem, motivando o paciente com câncer a lutar por sua recuperação (G. Santos et al., 2020).

Ao indagar-se sobre o que as pacientes consideravam um fator de apoio para lidar com o câncer ou quais as principais mudanças que ocorreram após a descoberta da doença, elas expuseram a falta que sentiam das pessoas mais próximas.

Ao surgir a confirmação do câncer, também é possível que ocorra a aproximação entre os familiares, num outro momento, distantes ou de pouco contato:

Principal mudança? A principal mudança que aconteceu... Meus filhos se aproximou mais de mim, né? Ficaram mais... Não é um lado que eu gosto, tá? Não gosto. Fica me bajulando...É, infelizmente, a gente tem hora, tem hora que a gente abusa dessa bondade, desse... né? A gente se acomoda... vai se acomodando. Tem hora que eu tenho que dar um... 'Pára, né?' Porque tudo na mão, tudo... Cê vai ficando sem vergonha [...] (P1)

Percebe-se que o apoio social torna-se agente motivador para lutar e resistir ao câncer, possibilitando ao paciente viver momentos de quietude e esperança em meio ao difícil processo de enfrentamento da doença. Embora fosse desagradável estar distantes das pessoas que amavam e com quem costumavam compartilhar os bons momentos da vida, as entrevistadas se viam, naquele momento, apegadas ao sentimento afetivo para se recuperarem do câncer e voltarem à sua antiga rotina com estas pessoas.

Com as entrevistas, visualizamos este cenário de forma clara e conseguimos identificar o quanto o apoio social causa grande diferença no duro percurso de confrontação do câncer.

\section{Dependência, uma nova realidade}

No decorrer das entrevistas, foi possível observar o profundo incômodo que a maioria das participantes sentia por, devido ao câncer, se tornarem dependentes de outras pessoas para executar, inclusive, as tarefas mais simples de seu cotidiano. Em algumas falas, ficou evidente esse desconforto:

Tabela 2 - A dependência provocada pelo câncer 


\section{Paciente Relato}

P6 Foi aos poucos [a adaptação no decorrer do adoecimento e tratamento], viu? É [...] comportamento diferente; você não pode mais fazer suas atividade, você vai tomar um banho e vai ter que ser com a ajuda das pessoa... Muda muito [...]

P5

[...] Depois que eu recebi a notícia que eu tive metástase de pulmão... aí minha vida mudou porque eu não consigo fazer mais nada. Eu tenho um filho de [...] 1 ano e 4 meses... Eu não faço nada em casa, então, assim, sou muito dependente dos outros. Então, assim, é difícil depender dos outros $[\ldots]$

[...] Eu dependo dos outros. Não faço nada por causa da metástase de pulmão porque tudo que eu vou fazer... Lavar uma louça, não consigo... Coisa tão simples... Eu não varro uma casa porque eu num... num consigo mais.

A hospitalização obriga o paciente com câncer a renunciar e modificar hábitos e rotina para que se tenha um tratamento eficaz. O difícil processo de enfrentamento da doença causa a gradual perda das capacidades física e psicológica, o que pode gerar um profundo choque no indivíduo (Santos et al., 2020).

O impacto provocado pelo diagnóstico e as consequências do tratamento pode modificar a capacidade funcional do corpo, prejudicando a realização das atividades cotidianas e causando mudanças na qualidade de vida dos pacientes. O câncer provoca mudanças na autonomia e independência, causando dificuldades. A dependência e a perda de identidade provocam sensações de angústia e medo, prejudicando o emocional e a qualidade de vida, sendo intensificado para quem vivencia o tratamento oncológico (Soratto, Silva, Zugno, \& Daniel, 2016).

Adaptar-se a tais mudanças não é de maneira alguma uma tarefa fácil. Estabelecer novos limites e reorganizar a rotina é um feito complexo que desperta insegurança e medo, porém é necessário para um tratamento que é demorado, exaustivo e doloroso. O diagnóstico de uma neoplasia maligna e tudo que o acompanha é capaz de romper o equilíbrio do indivíduo (Justino et al., 2014).

O processo de adoecimento é sofrido e angustiante e provoca, além das mudanças na rotina e na qualidade de vida, transformações no nível espiritual do sujeito, isto é, a fé do paciente oncológico pode proporcionar força, superação dos desafios, conforto e esperança no decorrer dos processos de adoecimento e tratamento, possibilitando maior significado na vivência determinada 
pelo câncer, uma vez que o paciente passa por diversas fases e sentimentos e coloca a fé como parte do tratamento, por exemplo, quando este perde as forças para lutar contra a doença. Em suma, a fé ou espiritualidade proporciona a sustentação quando não se consegue mais avançar, ou seja, eleva-se a um nível de maior intensidade (Soratto et al., 2016).

\section{Cura pela fé}

Nesta categoria, destaca-se a fé que a maioria das participantes revelou ter em relação à sua cura do câncer. Mesmo diante de um diagnóstico pouco animador, as participantes se empenhavam em acreditar que o câncer deixaria de se espalhar pelo corpo e elas poderiam seguir suas vidas livres do problema. Seja praticante de uma religião ou não, suas falas evidenciaram o fato:

Tabela 3 - A percepção da fé no processo de enfrentamento da doença

\begin{tabular}{ll}
\hline Paciente & Relato \\
\hline P3 & {$[\ldots]$ eu tenho tanta fé que eu sei que eu vou sair dessa. } \\
P4 & {$[. .$.$] Então, a gente tem que se apegar mais em Deus, mesmo. Se apegar$} \\
& mais em Deus pra Deus dá força e... superar tudo essa situação. E [...] \\
& o milagre pode... Muitos já foi até curado, né? Muitos curado do câncer, \\
& então eu creio na cura. \\
& {$[\ldots]$ Eu tenho fé que eu vou ser curada [...] A luta tá sendo grande, mas a } \\
P5 & {$[. .$.$] E a verdade, eu acho, que já tô é curada. Acho que isso é uma$} \\
besterinha qualquer que vai passar logo, se Deus quiser. Acho assim.
\end{tabular}

Quando a Medicina não apresenta uma saída considerável ao indivíduo, o mesmo recorre a outro método de cura, sendo assim, a religião e suas práticas são consideradas importantes ferramentas neste processo, tornando a fé um itinerário essencial. Através do conceito de cura espiritual, considera-se que o tratamento ocorre por forças e energias não-físicas. O processo desse tipo de cura se dá pela união do enfermo e as forças espirituais. Por meio da fé, a cura é resultado de um processo divino (Oliveira, 2016).

No contexto de saúde e doença, o indivíduo pratica sua fé com mais intensidade, buscando alívio e cura. A condição psíquica do sujeito pode indicar o surgimento e a gravidade de enfermidades, assim como a recuperação e a cura. Práticas religiosas, exercício da fé e busca por 
métodos não-materiais podem promover a renovação e sustentação, favorecendo o enfrentamento da dificuldade e da doença e oferecendo novos sentidos aos acontecimentos da vida (Souza, 2009).

Salientamos que a fé aqui não desconsidera ou anula a Medicina e todas as suas técnicas de tratamentos de doenças. Os processos de tratamentos de recuperação do câncer são essenciais e primordiais para qualquer indivíduo que receba tal diagnóstico, entretanto a fé, as práticas religiosas ou o relacionamento com uma divindade podem entrar em conjunto com tais técnicas, sendo consideradas medidas simultâneas de tratamento (Souza, Freitas, Faria, Cunha, Araújo, \& Veras, 2017).

As participantes da pesquisa acreditavam piamente em suas curas por meio da fé, ainda que não entendessem questões complexas voltadas para espiritualidade ou religiosidade. Algumas das pacientes acreditavam que necessitavam se apegar mais a sua divindade, pois não eram íntimas o suficiente dela, e outras não liam frequentemente a Bíblia ou faziam orações enfáticas em seu cotidiano, mas, mesmo assim, tinham fé que sairiam daquela situação, em breve, voltando a sua rotina de vida sem o câncer.

Diante disto, a fé torna-se alento para lidar com momentos difíceis da vida, tornando-se uma importante aliada às pessoas que passam por sofrimento (Soratto et al., 2016).

\section{Religião em prática}

A religião pode ser descrita pela forma que o indivíduo segue as suas crenças e filosofias, conectando-se ao sagrado. Independente do tipo de religião, quem busca a religiosidade se sente mais esperançoso, confiante e menos estressado, promovendo melhor recuperação de doenças (Rizzardi, Teixeira, \& Siqueira, 2010).

Outra percepção em relação às práticas religiosas corresponde aos hábitos, crenças e rituais que a pessoa diagnosticada com neoplasia maligna procura praticar para manter a motivação, como orações, rezas e leituras:

Tabela 4 - Manutenção de práticas religiosas

\begin{tabular}{ll} 
Paciente & Relato \\
\hline P1 & Ah, com certeza, não sei ficar sem [orações, rezas ou outros]. É como \\
& se fosse... é um adubo; se eu não tiver isso daí, eu num... é como se eu \\
& não sobrevivesse [...]
\end{tabular}

P3 Leio a Bíblia, leio revista; eu leio muito. Gosto muito de ler! [...] 
P4

P6

P7
É, assisto uma Palavra [Bíblia], né? Tudo é a Palavra. A Palavra de Deus sempre é bom, né? [...]

[...] eu rezo o terço na minha casa [...] Todo dia 13.

Direto [faz leitura de escrituras religiosas], tem até site no meu celular... que eu leio a Bíblia [...]

Ocorre uma melhora nos sinais de saúde mental, adaptação ao estresse e motivação na vida cotidiana através de práticas religiosas. Para muitos, as crenças conduzem para o alívio e a esperança (Rizzardi et al., 2010).

Embora, após as longas entrevistas, entendamos que praticar uma religião não seja fator decisivo para se ter fé, podemos observar que aquelas pacientes que costumavam frequentar uma instituição religiosa, fazer leituras constantes da Bíblia, livros religiosos e afins ou estavam em conexão com a sua divindade por meio de orações, rezas ou conversas informais diariamente, demonstraram uma intensidade maior não apenas em conhecimentos espiritual e religioso, mas em motivação e disposição no enfrentamento e na cura do câncer. Apesar de o tempo que seguiam suas religiões foi de pouca ou nenhuma influência nesta categoria, haja vista que a maioria das entrevistadas seguia a sua religião desde o nascimento, aquelas que praticavam os ritos e rituais com mais afinco, experimentavam sensações diferentes e nos permitiam enxergar um semblante mais entusiasmado, assim como pronunciavam frases de força e determinação muito mais contundentes.

As crenças e práticas religiosas evocam emoções positivas no sujeito e tais aspectos devem ser compreendidos, valorizados e considerados para um cuidado de saúde individualizado e singular. Cultivar os valores que promovam a virtude da fé pode contribuir diretamente para redução do estresse situacional e a ansiedade do doente (Sousa et al., 2017).

\section{Relacionamento com a divindade}

A ideia de divindade caracteriza-se pela conexão a uma figura de Deus ou a uma fonte de energia divina (Oliveira, Pascalicchio, \& Primi, 2012).

Na Bíblia Sagrada, Deus não recebe uma definição única e específica, mas, ao longo de todo o livro, Ele recebe características como "Criador" (Gênesis, 1:1), "Todo Poderoso" (Gênesis, 17:1), “A fonte da vida" (Salmos, 36:9), "Rei” (1 Timóteo 6:15), “Amor” (1 João 4:8), dentre diversas outras.

A divindade foi nomeada pelas participantes de diferentes formas: Pai maior, Jesus e Maria, Mestre e Senhor, Todo Poderoso, Deus e Jeová. As entrevistadas referiram-se à divindade com base naquilo que lhes foi apresentado ou no conhecimento e entendimento que possuíram sobre 
ela ao longo da vida. Embora algumas das pacientes não conseguissem definir ou descrever sua divindade, não negavam sua existência e a importância que desenvolviam em suas vidas e, principalmente, em situações difíceis como as que envolvem problemas de saúde.

No ambiente hospitalar, as pessoas submetidas a tratamentos como os de câncer, por exemplo, tendem a refletir mais sobre si e sobre os acontecimentos que as envolvem, uma vez que se veem em uma situação de vulnerabilidade e incertezas, o que traz diversas perguntas à mente, como já destacamos aqui. Para entender questões de alta complexidade, como "Qual o sentido de tudo isso?" ou "Por que isso está acontecendo comigo?", muitas buscam as respostas através da sua divindade, além do consolo e aceitação do câncer, delineando a essência da vida:

Tabela 5 - Respostas obtidas através da divindade

\begin{tabular}{|c|c|}
\hline Paciente & Relato \\
\hline P1 & $\begin{array}{l}\text { Creio.. creio no nosso Pai maior: foi Jesus e Maria. [O que eles representam } \\
\text { na vida] Bom, toda minha história; história da minha passagem na Terra. É, } \\
\text { é o caminho que me leva a desvendar o que eu tô fazendo aqui na Terra... } \\
\text { Qual é a minha missão, é isso aí. }\end{array}$ \\
\hline P4 & $\begin{array}{l}\text { [...] sabe o que faz fortalecer? Deus. Ele tá no controle, que cuida da } \\
\text { gente... Porque se não fosse Ele nessa hora, ia tá desesperado [...] E se } \\
\text { você não se... tem um contato diretamente com Deus... né? Sua fé fica } \\
\text { abalada, né? E quando você tá em ciência com Deus, aquele que Deus fez } \\
\text { por você, né? Tá cuidando de você [...] }\end{array}$ \\
\hline P5 & $\begin{array}{l}\text { [...] Mas, assim, mas com muita fé, eu me apeguei a muito a Deus. Se Ele } \\
\text { permitiu essa prova que eu vou passar, eu vou conseguir. }\end{array}$ \\
\hline P6 & $\begin{array}{l}\text { [...] Ele tá sendo tudo na minha vida. Acho que eu tô aqui por causa de } \\
\text { Deus. Se não fosse Deus, eu não tava aqui [...] }\end{array}$ \\
\hline
\end{tabular}

Aos poucos, a ciência vem reconhecendo o papel da espiritualidade na dimensão do ser humano. Na segunda Conferência Internacional sobre Promoção da Saúde, a OMS incluiu a dimensão espiritual no conceito multidimensional de saúde, demonstrando a sua importância como elemento fundante da condição humana (WHO, n.d.).

O ser humano busca significados, sobretudo no que está em si e ao seu redor, procurando ser completo e preenchido nos diversos âmbitos da vida. Neste caso, a espiritualidade proporciona uma relação entre a pessoa e a força superior que ela acredita (Barbosa \& França, 2019).

A espiritualidade faz bem à mente e ao corpo, tornando-se equilíbrio existencial para o homem que crê na sua existência como desejo de uma divindade (Barbosa \& França, 2019). 
Em algumas falas das entrevistadas, demonstraram entender que o delicado momento que atravessavam era permissão de sua divindade, seja para um aprendizado em sua vida ou encaravam como uma missão que tem propósito na vida do próximo:

Tabela 6 - Percepção da permissão do câncer pela divindade

\begin{tabular}{ll}
\hline Paciente & Relato \\
\hline P2 & [...] Assim, no meu pensamento, pode ser que seja que eu tenho que \\
& passar por isso [sobre a expectativa em relação à doença], né? [...] \\
& ninguém vai passar por mim. Ou deve ser também a parte espiritual, \\
& também, né? [...] \\
& Ah, [...] fiquei triste [sobre adaptação no decorrer do adoecimento e \\
& tratamento], depois eu falei: 'Não, não posso ficar triste. Deus dá aquilo \\
& que a gente... que... eu tô merecendo.' Às vezes, a... eu mereço pra \\
& acontecer isso pra eu ser uma pessoa bem melhor do que eu sou... Eu \\
& imagino isso. [...] \\
& [...] Então, assim, é difícil cê depender dos outros. Mas... se Deus tá \\
& permitindo tudo isso, porque lá na frente eu tenho uma vitória pra \\
& contar.
\end{tabular}

Com isso, entendemos que as pacientes atribuem à sua divindade não uma culpa por estarem doentes, mas uma dependência espiritual, onde depositam nela a confiança de suas vidas e de seus destinos. Embora as circunstâncias fossem desalentadoras, elas criam que o ser divino que lhes permitiu ficar doentes, era o mesmo que as curaria, nas palavras de algumas, essa cura já existia e elas estavam seguindo em direção à ela.

\section{Resiliência e a potencialização da fé}

Resiliência é um fenômeno construído de forma gradativa a partir das situações vivenciadas pelo indivíduo e o seu ambiente. Trata-se da capacidade que o ser humano tem de construir uma trajetória de vida saudável, independente de as condições atuais serem desfavoráveis. A resiliência não anula ou elimina a situação de risco, mas é resultado de enfrentamento, com sucesso, de uma situação adversa (Silva, Lunardi, Filho, \& Tavares, 2005).

O significado de resiliência caracteriza-se pela capacidade de recuperação das adversidades, força, resistência e superação do processo de adoecimento. A resiliência pode se tornar uma forma de enfrentamento de cada paciente diante do seu diagnóstico, dando significado 
no seu processo cura-doença através da ligação com a fé, aliviando o sofrimento e resultando em expectativas de cura no decorrer do tratamento (Soratto et al., 2016).

Como já destacado ao longo deste estudo e pontuado nas categorias acima, a promoção da fé, independente da religião, é primordial no enfrentamento do câncer, uma vez que esta torna-se base que potencializa a segurança e a esperança de que o sujeito acometido de tal enfermidade venha a se curar e volte a ter uma vida saudável.

Quando o paciente já não vê mais solução no tratamento ou o processo torna-se doloroso ao ponto de desanimá-lo, ele se agarra a sua fé, exercida de maneira muito particular, para continuar a jornada de enfrentamento da neoplasia. E, embora algumas das pacientes já seguissem uma religião desde o seu nascimento, nem sempre elas a praticaram ao longo de suas vidas, mas diante do duro diagnóstico do câncer, elas se voltaram para as suas crenças espirituais novamente e se permitiram viver este momento com fé de que iam se recuperar da doença. Em confluência, os termos resiliência e fé carregam em si sentidos iguais ou parecidos ao buscarem objetivos em comum como a superação da doença que aflige o indivíduo.

A religião tem se revelado particularmente relevante como estratégia de enfrentamento de situações adversas, sendo a fé religiosa apontada como uma importante fonte de resiliência (Margaça \& Rodrigues, 2019).

Algumas das entrevistadas destacaram que, após receber o diagnóstico do câncer, a fé aumentou, consequentemente impulsionando-as a realizar práticas religiosas com maior frequência e motivando-as a crer com maior dedicação na cura:

Tabela 7 - Aumento da fé pós diagnóstico

\begin{tabular}{ll} 
Paciente & Relato \\
\hline P5 & Eu acho que a minha fé aumentou mais ainda. Já... já tinha muita fé em \\
& Deus e, hoje, aumentou mais. Eu acredito em milagre... E eu já sou um \\
& milagre, né? [...] \\
& [...] Então, a gente tem que se apegar mais em Deus, mesmo. Se apegar \\
P4 & mais em Deus pra Deus dá força e.... superar tudo essa situação. [...] \\
& Mudou [a espiritualidade/religiosidade/fé após o diagnóstico da doença], \\
& assim, eu fiquei... é... eu fiquei me punindo [...] Aí eu comecei a ficar \\
& me culpando, assim, pouquinho só, depois passou. É... pensando \\
& assim: 'Poxa vida! Eu..., tipo, só fiquei fazendo outras coisas... fui \\
& deixando uma coisa mais importante de lado. Aí que agora eu vou \\
& prestar mais atenção.
\end{tabular}

Rev. Psicol Saúde e Debate. Set., 2021:7(1): 214-235. 
O câncer é estigmatizado como uma doença que traz o sofrimento físico além dos sentimentos de tristeza, indignação e angústia mantidos no pensamento do paciente que se vê constantemente com medo diante da ameaça de morte pelo duro diagnóstico de uma neoplasia maligna. Esses sentimentos podem se intensificar e até dificultar para que o paciente siga adiante com o tratamento e a esperança de cura, entretanto a tensão desse problema pode ser aliviada com estratégias de enfrentamento sugeridas pela literatura, dentre elas, a fé e as crenças religiosas (Guerrero et al., 2011).

\section{CONSIDERAÇÕES FINAIS}

O câncer é uma doença que tem alcançado altos índices mundiais de casos e óbitos no decorrer dos anos. Apesar de existirem diversos tratamentos eficazes para eliminar a doença, o câncer ainda traz consigo sentimentos aflitivos e desperta pensamentos complexos no indivíduo que recebeu o diagnóstico, que na maioria das vezes são difíceis de compreender e/ou associar.

A neoplasia maligna também provoca mudanças na autonomia e independência do sujeito, pois prejudica a capacidade funcional do corpo por causa dos invasivos e agressivos procedimentos do tratamento, interferindo na realização de atividades corriqueiras do paciente.

As pacientes entrevistadas relataram o desconforto e o incômodo que sentiam por terem que depender de outras pessoas naquela fase de suas vidas. Todavia, observamos que as pacientes que recebiam o apoio de familiares, amigos e outros, conseguiam enfrentar o câncer com mais esperança e coragem; elas demonstraram se sentir mais seguras e protegidas, além de amadas. Já aquelas que não contavam com o mesmo apoio ou nenhum tipo de auxílio, se mostraram mais desanimadas diante do diagnóstico.

Dentre as técnicas de tratamentos disponíveis, a fé tem sido uma das principais aliadas, a qual o paciente diagnosticado com câncer tem se agarrado para superar este momento difícil. Embora tenhamos observado que seguir ou não uma religião não era um fator decisivo para se ter fé, concluímos que praticar os ritos e rituais da religião a intensificavam, potencializando assim a esperança na cura.

Com as entrevistas, percebemos que as pacientes que tinham hábitos ativos de sua religião, buscando manter um relacionamento com a sua divindade, apresentaram um semblante mais animado e esperançoso. Embora os sentimentos de uma pessoa não possam e nem devam ser medidos por aquilo que se observa a olho nu, entendemos que o corpo físico reflete o íntimo, isto é, aquilo que se sente interiormente pode ser visível no exterior do ser humano. Mantendo a religião em prática, as pacientes demonstraram força e resistência, independente do contexto que se encontravam e do que ainda estava por vir; elas acreditavam que seriam curadas e tinham fé que esta cura estava próxima. 
Posto que a fé não é essencial apenas como apoio a pacientes diagnosticados com câncer ou qualquer outra enfermidade, sendo considerada importante em outros momentos da vida de uma pessoa por motivar a crer naquilo que, devido às circunstâncias, parece impossível de se alcançar, essa crença é capaz de impulsioná-la na busca pela recuperação e superação de todas as adversidades que se apresentarem no decorrer da vida. Sendo assim, observamos uma resiliência encorajadora nas pacientes que declararam que a fé aumentou após o diagnóstico, o que é confirmado pela literatura, sendo assim, a fé potencializa a resiliência.

O relacionamento com a divindade, assim como os relacionamentos que mantemos ao longo de nossas vidas, são muito particulares e requerem intimidade e dedicação. Ouvimos os relatos das pacientes que acreditavam na existência sobrenatural de uma divindade e, num aspecto mais amplo, sentiam e conversavam com ela, além de buscarem na divindade e na religião as respostas de perguntas complexas e existenciais que surgiam com o diagnóstico do câncer e tudo que o envolvia. Na percepção delas, a doença se manifestou como permissão da divindade na qual acreditavam; algumas entendiam que havia um propósito maior, outras não sabiam dizer o porquê de toda a situação, mas aceitavam, e criam que a sua divindade as ajudava naquele processo e as conduzia para a cura da doença, tornando-as pessoas vitoriosas sobre o câncer.

Por fim, concluímos que a fé exerce influência positiva ao longo do tratamento do paciente oncológico e infere efetivamente na qualidade de vida do indivíduo. E os pacientes diagnosticados com câncer que praticam a fé (expressão religiosa) tendem a ter maiores benefícios no tratamento da doença.

\section{REFERÊNCIAS}

Alves, R. F., Melo, M. O., Andrade, S. F. O., Fernandes, T. S., Gonçalves, D. L., Freire, A. A. (2012). Qualidade de vida em pacientes oncológicos na assistência em casas de apoio. Aletheia, 3839. Recuperado de http://pepsic.bvsalud.org/scielo.php?script=sci arttext\&pid=S141303942012000200004.

Alves, R. F., Silva, R. P., Ernesto, M. V., Lima, A. G. B., Souza, F. M. (2011). Gênero e saúde: o cuidar do homem em debate. Psicologia: teoria e prática, 13(3). Recuperado de http://pepsic.bvsalud.org/scielo.php?script=sci arttext\&pid=S1516-36872011000300012.

Barbosa, M. D. S., França, G. S. D. (2019). Enfermagem e espiritualidade/religiosidade na assistência ao paciente em tratamento oncológico: revisão integrativa. Palmeira dos Índios, AL. Recuperado de https://ri.cesmac.edu.br/handle/tede/548.

Centro de Combate ao Câncer. (n.d.). O que é quimioterapia. Recuperado de http://www.cccancer.net/tratamento/o-que-e-quimioterapia/.

Centro de Combate ao Câncer. (n.d.). $O$ que é radioterapia. Recuperado de http://www.cccancer.net/tratamento/o-que-e-radioterapia/.

Cerqueira-Santos, E., Koller, S. H., Pereira, M. T. L. N. (2004). Religião, saúde e cura: um estudo entre neopentecostais. Psicologia: ciência e profissão, 24(3), 82-91. Doi: 10.1590/S1414-

Rev. Psicol Saúde e Debate. Set., 2021:7(1): 214-235. 
Christo, Z. M., Traesel, E. S. (2009). Aspectos psicológicos do paciente oncológico e a atuação da psico-oncologia no hospital. Disciplinarum Sciential Ciências Humanas, 10(1), 75-87. Doi: 10.37780/ch.v10i1.1694

Conselho Nacional de Saúde. (2012). Resoluções. Recuperado de http://conselho.saude.gov.br/resolucoes/2012/Reso466.pdf.

Deslandes, S. F. (2002). A construção do projeto de pesquisa. In M. C. S. Minayo (Org.), Pesquisa social - Teoria, método e criatividade (p. 43). Petrópolis: Vozes.

Fabiani, L., Quadros, M. N., Eichelberger, M. A., Bocchese, A., Santiago, P., Silva, J. A. C. (2019). Influência da presença de metástase no perfil de mortalidade de pacientes oncológicos. Revista Eletrônica Acervo Saúde, 11(5). Doi: 10.25248/reas.e345.2019

Farinhas, G. V., Wendling, M. I., Dellazzana-Zanon, L. L. (2013). Impacto psicológico do diagnóstico de câncer na família: um estudo de caso a partir da percepção do cuidador. Pensando famílias, 17(2), 111-129. Recuperado de http://pepsic.bvsalud.org/scielo.php?script=sci arttext\&pid=S1679-494X2013000200009.

Ferreira, A. P. D. Q., Lopes, L. Q. F., Melo, M. C. B. D. (2011). O papel do psicólogo na equipe de cuidados paliativos junto ao paciente com câncer. Revista da SBPH, 14(2), 85-98. Recuperado de http://pepsic.bvsalud.org/scielo.php?script=sci arttext\&pid=S1516-08582011000200007.

Fontanella, B. J. B., Ricas, J., Turato, E. R. (2008). Amostragem por saturação em pesquisas qualitativas em saúde: contribuições teóricas. Cadernos de saúde pública, 24, 17-27. Recuperado de https://www.scielosp.org/article/csp/2008.v24n1/17-27/.

Gayer, C. J. T. (2013). A influência da espiritualidade e da religiosidade na vivência dos pacientes. Belo Horizonte, BH: Universidade Federal de Minas Gerais.

Gomes, R., Nascimento, E. F., Araújo, F. C. (2007). Por que os homens buscam menos os serviços de saúde do que as mulheres? As explicações de homens com baixa escolaridade e homens com ensino superior. Cadernos de Saúde Pública, 23(3). Doi: 10.1590/S0102311 X2007000300015

Guerrero, G. P., Zago, M. M. F., Sawada, N. O., Pinto, M. H. (2011). Relação entre espiritualidade e câncer: perspectiva do paciente. Revista Brasileira de Enfermagem, 64(1), 53-59. Doi: $10.1590 /$ S0034-71672011000100008

Instituto Nacional de Câncer. (2020). Estimativa 2020. Recuperado de https://www.inca.gov.br/estimativa/introducao.

Instituto Nacional de Câncer. (2021). Conceito e Magnitude do câncer de mama. Recuperado de https://www.inca.gov.br/controle-do-cancer-de-mama/conceito-e-magnitude.

Instituto Nacional de Câncer. (n.d.). Todo tumor é câncer?. Recuperado de https://www.inca.gov.br/perguntas-frequentes/todo-tumor-e-cancer.

Justino, E. T., Mantovani, M. F., Kalinke, L. P., Ulbrich, E. M., Moreira, R. C., Abini, L. (2014). A trajetória do câncer contada pela enfermeira: momentos de revelação, adaptação e vivência da cura. Escola Anna Nery, 18(1). Doi 10.5935/1414-8145.20140006

Malzyner, A. (2013). Importância do diagnóstico precoce e recomendações. In A. Malzyner \& R. 
Caponero (Orgs.), Câncer e prevenção (pp. 51-52). São Paulo: MG Editores.

Margaça, C., Rodrigues, D. (2019). Espiritualidade e resiliência na adultez e velhice: uma revisão. Fractal: Revista de Psicologia, 31(2). Doi 10.22409/1984-0292/v31i2/5690

Minayo, M. C. S. (2002). Ciência, técnica e arte: o desafio da pesquisa social. In M. C. S. Minayo (Org.), Pesquisa social - Teoria, método e criatividade (pp. 21-22). Petrópolis: Vozes.

Minayo, M. C. S. (2006). Técnicas de Análise de Dados. In M. C. S. Minayo (Org). O desafio do conhecimento: pesquisa qualitativa em saúde (p. 216). Petrópolis: Vozes.

Oliveira, K. L, Pascalicchio, M. L., Primi, R. (2012). A inteligência espiritual e os raciocínios abstrato, verbal e numérico. Estudos de Psicologia, 29(1). Doi 10.1590/S0103-166X2012000100002

Oliveira, P. L. A. D. (2016). A fé como recurso de cura: Uma revisão integrativa. Brasília, DF. Recuperado de https://bdm.unb.br/bitstream/10483/14021/1/2016 PaulaLorranyAlvesdeOliveira.pdf.

Ouro, G. C., Sodré, B. C., Figueiredo, E. G. C., Souto, L. A. D., Fernandes, M. T. T., Fernandes, M. T. (2018). Análise da influência da fé, espiritualidade e religião no prognóstico de pacientes com câncer. Revista Saúde \& Ciência Online, 7(2), 125-132. Doi: 10.35572/rsc.v7i2.101

Rizzardi, C. D., Teixeira, M. J., de Siqueira, S. R. D. T. (2010). Espiritualidade e religiosidade no enfrentamento da dor. Recuperado de https://www.researchgate.net/profile/Silvia Siqueira2/publication/318289203 Espiritualidade e religiosidade no enfrentamento da dor/links/5a742fa70f7e9b20d490a8b9/Espiritualidadee-religiosidade-no-enfrentamento-da-dor.pdf.

Saad, M., Masiero, D., Battistella, L. R. (2001). Espiritualidade baseada em evidências. Acta Fisiátrica, 8(3), 107-112. Doi: 10.5935/0104-7795.20010003

Santana, J. J. R. A. D., Zanin, C. R., Maniglia, J. V. (2008). Pacientes com câncer: enfrentamento, rede social e apoio social. Paidéia (Ribeirão Preto), 18(40), 371-384. Doi: 10.1590/S0103863X2008000200013

Santos, G. B. S., Santos, B. B. D., Melo, J. D. S. (2020). A percepção da pessoa internada sobre sua vivência no hospital. Revista do NUFEN, 12(2), 1-19. Recuperado de http://pepsic.bvsalud.org/scielo.php?script= sci arttext \& pid=S2175-25912020000200002.

Sette, C. P., Capitão, C. G. (2018). Efeito moderador do suporte social em pacientes oncológicos. Psicologia, Saúde \& Doenças, 19(2), 265-277. Doi: 10.15309/18psd190209

Silva, M. R. S., Lunardi, V. L., Filho, W. D. L., Tavares, K. O. (2005). Resiliência e promoção da saúde. Texto \& Contexto - Enfermagem, 14(spe). Doi 10.1590/S0104-07072005000500012

Silva, R. D. C. V. D., Cruz, E. A. D. (2011). Planejamento da assistência de enfermagem ao paciente com câncer: reflexão teórica sobre as dimensões sociais. Escola Anna Nery, 15(1), 180-185. Doi: 10.1590/S1414-81452011000100025

Silva, S. D. S., Aquino, T. A. A. D., Santos, R. M. D. (2008). O paciente com câncer: cognições e emoções a partir do diagnóstico. Revista brasileira de terapias cognitivas, 4(2), 73-89. Recuperado de http://pepsic.bvsalud.org/scielo.php?script=sci arttext\&pid=S1808$\underline{56872008000200006}$.

Soratto, M. T., Silva, D. M., Zugno, P. I., Daniel, R. (2016). Espiritualidade e Resiliência em 
Pacientes Oncológicos. Saúde E Pesquisa, 9(1), 53. Doi: 10.17765/2176-9206.2016v9n1p5363

Sousa, F. F. P. R. D., Freitas, S. M. F. M., Farias, A. G. S., Cunha, M. C. S. O., Araújo, M. F. M., Veras, V. S. (2017). Enfrentamento religioso/espiritual em pessoas com câncer em quimioterapia. SMAD. Revista Eletrônica Saúde Mental Álcool e Drogas, 13(1). Doi 10.11606/issn.1806-6976.v13i1p45-51

Souza, M. A. D. (2009). A influência da fé no processo saúde-doença sob a percepção de líderes religiosos cristãos (Dissertação de mestrado, Faculdade de Enfermagem, Universidade Federal de Goiás). Recuperado de https://repositorio.bc.ufg.br/tede/handle/tde/688.

World Health Organization. (2018). Câncer. Recuperado de https://www.who.int/news-room/factsheets/detail/cancer.

World Health Organization. (n.d.). Adelaide Recommendations on Healthy Public Policy. Recuperado de https://www.who.int/healthpromotion/conferences/previous/adelaide/en/\#. 